\title{
Constrictive pericarditis with pericardial calcification
}

\author{
Kevin R. An MD, Steve K. Singh MD MSc
}

Cite as: CMAJ 2021 June 7;193:E853. doi: 10.1503/cmaj.202346

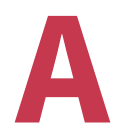

71-year-old man with a history of a locally excised melanoma presented to his family physician with 2 years of progressive lower leg edema, ascites, weight loss, fatigue and dyspnea on exertion. His medical history also included a protracted, flulike illness 3 years prior. As part of a workup for recurrent melanoma that was otherwise unremarkable, a computed tomography scan of the patient's chest showed pericardial and epicardial calcifications, consistent with a diagnosis of constrictive pericarditis (Figure 1A). A transthoracic echocardiogram showed a pericardial effusion, thickened pericardium, septal bounce and dilated inferior vena cava. Cardiac catheterization showed equalization of diastolic pressures in all 4 chambers at 20 (normal range 2-12) mm Hg, confirming constrictive pericarditis.

A pericardiectomy revealed a white calcific heart; we resected the pericardium anterior to the phrenic nerves bilaterally to relieve cardiac constriction (Figure 1B). Pathology showed no evidence of malignancy, and specimen cultures were negative for tuberculosis. Although causality cannot be firmly established, we consider it most likely that the constrictive pericarditis was a long-term sequela of a viral infection. The patient's presenting symptoms of abdominal distension, lower leg swelling, fatigue and shortness of breath steadily improved postoperatively, and he was discharged from hospital 2 weeks after surgery.

Constrictive pericarditis is a chronic inflammatory condition of the pericardium, with an incidence of 1 in 100000 in the United States. ${ }^{1}$ It is often initiated by idiopathic or viral pericarditis, previous cardiac surgery, mediastinal radiation or tuberculosis, and is thought to be triggered by an immune response, leading to the development of a fibrous or calcific pericardium. ${ }^{1,2}$ In one series, $28 \%$ of resected pericardium specimens were grossly calcified on pathology. ${ }^{3}$ Symptoms are similar to those of heart failure, and the condition is difficult to distinguish from restrictive cardiomyopathy. ${ }^{2}$ Bilateral cardiac catheterization is the gold standard diagnostic test, ${ }^{4}$ and definitive management is pericardiectomy.

\section{References}

1. Mori M, Mullan CW, Bin Mahmood SU, et al. US national trends in the management and outcomes of constrictive pericarditis: 2005-2014. Can J Cardiol 2019;35:1394-9.

2. Syed FF, Schaff HV, Oh JK. Constrictive pericarditis - a curable diastolic heart failure. Nat Rev Cardiol 2014;11:530-44.

3. Oh KY, Shimizu M, Edwards WD, et al. Surgical pathology of the parietal pericardium: a study of 344 cases (1993-1999). Cardiovasc Pathol 2001;10:157-68.

4. Welch TD, Oh JK. Constrictive pericarditis. Cardiol Clin 2017;35:539-49.

Competing interests: None declared.

This article has been peer reviewed.

The authors have obtained patient consent.

Affiliation: Division of Cardiac Surgery, Trillium Health Partners, University of Toronto, Toronto, Ont.

Content licence: This is an Open Access article distributed in accordance with the terms of the Creative Commons Attribution (CC BYNC-ND 4.0) licence, which permits use, distribution and reproduction in any medium, provided that the original publication is properly cited, the use is noncommercial (i.e., research or educational use), and no modifications or adaptations are made. See: https://creativecommons.org/licenses/by-nc-nd/4.0/

Correspondence to: Steve Singh, steve.singh@thp.ca 